\title{
COMO IMAGENS CINEMATOGRÁFICAS COM REDES DE CONVERSAÇÕES PODEM MOVIMENTAR CURRÍCULOS E FORMAÇÃO DE PROFESSORAS?
}

\section{HOW CINEMATOGRAPHIC IMAGES WITH CONVERSATION NETWORKS MOBILIZE CURRICULA AND TEACHER TRAINING?}

Sandra Kretli da Silva ${ }^{1}$

Marlucy Alves Paraíso

\begin{abstract}
Resumo: Este artigo apresenta fragmentos de uma pesquisa que buscou compor encontros com professoras para pensar a força das imagens cinematográficas em redes de conversações na movimentação de currículos. Problematiza como professores/as inventam processos de resistências às tentativas de padronização de currículos, realizando uma cartografia dos fluxos e forças engendradas no encontro de redes de conversações de professoras com imagens cinematográficas para pensar possibilidades de criação de linhas de vida para os currículos e as escolas. Argumenta que os encontros com as imagens cinematográficas seguidos de redes de conversações possibilitam a expansão de forças intensivas que acionam múltiplas sensações e provocam rupturas nos clichês e nas imagens dogmáticas do pensamento, potencializando a coletividade na invenção de novos modos de subjetivação e de resistências às redes de poderes que tentam aprisionar as forças inventivas que atravessam os cotidianos escolares.
\end{abstract}

Palavras-chave: Imagens-Cinema; redes de conversações; invenções curriculares.

\begin{abstract}
This paper presents excerpts of a study, which endeavored to hold meetings with teachers to think about the force of cinematographic images in networks of conversations in the mobilization of curricula. It questions how teachers create processes of resistance to the attempts of standardizing curricula, realizing a mapping of the flows and forces engendered in the meeting of teacher conversation networks with cinematographic images to think possibilities to create lines of life curricula and schools. It points out that encounters with cinematographic images followed by conversation networks enables the expansion of intensive forces that prompts multiple sensations and provoke ruptures in clichés and dogmatic images of thought. Thus, they potentialize the collectivity in the invention of new modes of subjectification and inventive resistances to the networks of powers, which try prevent inventive forces wich cross everyday school.
\end{abstract}

Keywords: Cinema-Images; conversation networks; curricular inventions.

\footnotetext{
${ }^{1}$ Professora Adjunta II do Departamento de Teorias e Práticas Educacionais na Universidade Federal do Espírito Santo, professora do Programa de Pós-Graduação em Educação (PPGE) e do Programa de Pós-Graduação Mestrado Profissional em Educação (PPGMPE) da Ufes; membro dos grupos de pesquisa GECC/UFMG e do grupo Com-Versações/Ufes; pesquisadora PDJ/CNPq. E-mail: sandra.kretli@ hotmail.com.

${ }^{2}$ Professora Titular da Faculdade de Educação da Universidade Federal de Minas Gerais e do Programa de PósGraduação em Educação: Conhecimento e Inclusão Social da mesma faculdade; fundadora e atual coordenadora do Grupo de Estudos e Pesquisas em Currículos e Culturas (GECC); bolsista de Produtividade em Pesquisa do CNPq, nível IC. E-mail: marlucyparaiso@gmail.com.
} 


\section{Introdução}

O destino do sonhador é duvidar.

Milton Hatoum

Milton Hatoum, no livro Um solitário à espreita, oferece-nos uma crônica intitulada Um sonhador. Conta a história das moças vaga-lumes, contadoras de histórias, que traziam palavras para um povoado. "As palavras não curam, mas são uma trégua no desamparo, melodia na solidão" (HATOUM, 2013, p. 222). Ressalta, também, que são as histórias das moças vaga-lumes que fazem as crianças sonharem. Em seguida, descreve outros fragmentos de um sonho que o levou a recordar uma frase inesquecível da sua vida: "o destino do sonhador é duvidar". Assim como as moças vagalumes que fazem as crianças de um povoado sonhar, desejamos que as imagens-cinema utilizadas como disparadoras das redes de conversas de professoras em processo de formação, seja fluxo de luz, jorro da diferença nas escolas, inspiradoras de sonhos e de invenções de vidas. Sonhos que nos fazem duvidar das inúmeras "verdades" fixadas para as escolas.

Este artigo apresenta fragmentos de uma pesquisa que buscou compor encontros com as professoras de dois centros municipais de educação infantil (Cmeis), localizados na capital do Espírito Santo, Vitória, fazendo "usos" de imagens cinematográficas para movimentar o pensamento e expandir a força das conexões e das combinações que movimentam as invenções curriculares. As reuniões com as professoras aconteceram quinzenalmente, durante um semestre. Participaram da pesquisa cinquenta e duas professoras, seis pedagogas e quatro pesquisadores. As reuniões tiveram como elemento disparador para as redes de conversações (CARVALHO, 2009) curtas-metragens e animações.

As redes de conversações se constituem em trocas de experiências vividas e compartilhadas, que se alimenta "[...] pela participação ativa, que combina em si duas dimensões: a poética da participação e a sociabilidade, articulando vozes, assuntos, em participação criativa" (CARVALHO, 2006, p. 282). A força dos encontros com as imagens-cinema provoca o desalojar do pensamento, fazendo circular a multiplicidade e a diferença que mobiliza os processos de subjetivações. Assim, nesse enredamento de conversas amplia-se os vínculos, o engajamento e a confiabilidade do grupo que se potencializa em busca de resistências coletivas aos processos de padronização do trabalho docente para inventar novas experimentações e invenções curriculares.

Um dos curtas exibidos para as professoras durante a cartografia foi a animação produzida na Malásia Changing Batteries, que significa, Trocando as Baterias. As imagens desse curta possibilitaram que as professoras, movidas pelos afectos e perceptos constituídos a partir do encontro com as imagens, problematizassem as relações sociais na atualidade e a necessidade de ativar a energia coletiva para expandir as redes de solidariedade, os processos de resistências e as inventividades curriculares nos cotidianos escolares.

Afecto, entendido com base em Spinoza (2008), que significa afecção corporal que pode aumentar ou diminuir a potência de agir, e pode variar conforme as intensidades dos encontros. Se os encontros são bons, eles trazem alegria e isso expande a potência. Se os encontros são ruins eles trazem tristezas e reduzem a força intensiva (SPINOZA, 2008). Percepto, por sua vez, é diferente de percepção. O percepto "[...] consiste numa atmosfera que excede as situações vividas e suas representações" (ROLNIK, 2018, p. 53). Os perceptos, não são as interpretações das imagens, mas manifestações de sensações, sentimentos, emoções e inquietações causadas pelas afecções dos signos artísticos no corpo.

$\mathrm{O}$ argumento desenvolvido neste artigo é o de que os encontros com as imagens cinematográficas, seguidos de redes de conversações, favorecem a expansão de forças que recarregam e impulsionam a coletividade na/da escola, e potencializam movimentos 
curriculares e processos de formação inventiva que criam resistências às políticas educacionais que tentam padronizar e regular o trabalho docente e os currículos escolares.

O currículo aqui é entendido como corpos coletivos (CARVALHO; SILVA. DELBONI, 2018, p. 208), que atua como potência de ação coletiva no cotidiano escolar, “[...] tomando seus intercessores como hipótese principal de que essa 'potência' depende fundamentalmente da capacidade de indivíduos e grupos se colocarem em relação para produzir e trocar conhecimentos". Os movimentos inventivos curriculares se constituem, portanto, em redes de conversas que emergem das afecções causadas pelas imagens-cinema. São esses fluxos de forças que provocam a desterritorialização nas prescrições curriculares, proporcionando as dúvidas, as problematizações e, assim, aberturas para reinvenção da escola.

A formação inventiva, por sua vez, é aquela que não segue padrões e nem normas das diretrizes curriculares ou da formação inicial. A formação inventiva se dá tendo como tema e conteúdo da formação as próprias dúvidas, sensações, problematizações, concepções, angústias e compreensões das professoras. Não está vinculada a disciplinas especificas, mas sim com problemas e questões que emergem do encontro das professoras com as imagens cinematográficas e pesquisadoras. Trata-se de uma formação que se envolve com a invenção de novas formas de ser e de estar no mundo, porque é impossível pensar em invenção sem pensar as suas implicações políticas (KASTRUP, 2012). Uma formação que se movimenta engendrada às redes de afectos que emergem dos encontros, das conexões e das forças das imagens cinematográficas em redes de conversações.

No cinema, as imagens são signos. O cinema faz nascer signos que lhes são próprios, mas, uma vez criados, eles voltam a irromper em outro lugar. Os cineastas fazem cinema, assim como nós, nos constituímos cineastas dos nossos tempos (DELEUZE, 2010). De que maneira nos colocamos diante do mundo? Como cineastas do nosso mundo, que imagens de escola temos produzido? Paraíso (2015, p. 55), inspirada no devir-artista da fada Docine, personagem criada por Hernán Letenier, afirma que:

[...] um currículo, apesar de ser constituído de muitas formas, pode perfeitamente ser feito da mesma matéria dos sonhos, dos filmes e da vida. Para isso é necessário fazer muitos cortes nas formas que aniquilam as forças; deformar as regras; arriscar; seguir o movimento da vida; atentar às sensações nossas e de nossos/as alunos/as. Um currículo, livre das formas que aprisionam, trabalha com a diferença para encontrar os desejos dos diferentes, para enfatizar as suas dinâmicas, reforçá-las e problematizá-las.

As imagens exibidas na animação "Trocando as baterias" possibilitaram o encontro com o intempestivo e a compreensão da importância da amizade e das relações que ativam a potência das redes de afectos e afecções no espaço escolar para revitalizar o trabalho coletivo, as resistências coletivas e as invenções curriculares. O intempestivo é o inusitado, aquilo que causa estranheza, provoca inquietude, pois desestabiliza as formas vigentes. É o imprevisível, que provoca abertura para os possíveis, para as invenções. A abertura que as imagens desse curta provocou na pesquisa foi pensarmos em maneiras de fazer uma poética da docência, uma docência mais autônoma e inventiva que se constitui por meio dos encontros, numa política da amizade e da solidariedade. 


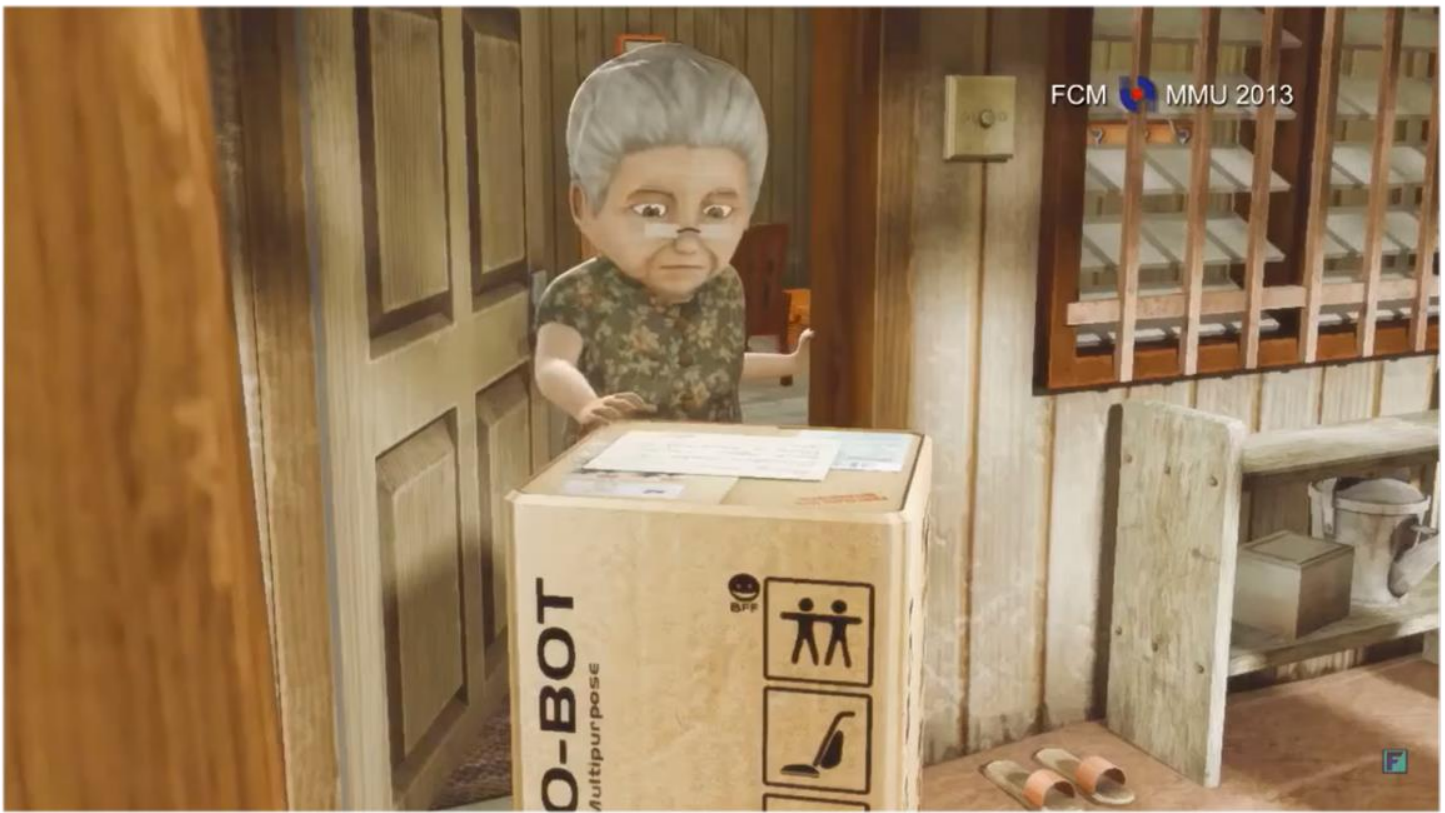

Imagem 1: Um robô para lhe fazer companhia e lhe ajudar nos afazeres diários

Fonte: https://www.youtube.com/watch?time_continue=286\&v=O_yVo3YOfqQ\&feature=emb_logo

O curta dirigido por Shu Gi, Casandra Ng, JiaHui e Bahareh Darvish, conta a história de uma senhora idosa que recebe de presente do seu filho um robô e um bilhete com as justificativas de sua ausência. No bilhete, havia uma explicação de que o robô serviria para fazer companhia e ajudar a mãe nos afazeres diários. Naquele momento da pesquisa, ainda não havia o Coronavírus ${ }^{3}$ no ar, porém, as professoras afetadas pelas imagens da animação, expressaram a respeito de outros vírus que desgastam a força coletiva da escola: a falta de interação e de diálogo. Ressaltam, ainda, a importância das relações cotidianas e das trocas de experiências para a expansão do trabalho coletivo. Uma professora diz:

A gente se enrola com tantas coisas e interagimos tão pouco. Aí a gente manda um presentinho, né? Aí, nos deparamos com a mesma ideia de mercadoria, vamos sendo descartados, como se a gente não tivesse mais utilidade, um presentinho basta. Dou um robô para a minha mãe e um celular para a criança. Assim, ninguém cuida de ninguém!!!

A professora destaca a importância de pensarem a lógica do mercado que tomou conta das nossas vidas. Com o consumo desenfreado, os materiais, assim como a vida, tornam-se descartáveis. O filme vidas descartáveis, dos diretores Alexandre Valenti e Alberto Graça, também foi ressaltado para nos lembra das condições precárias que os trabalhadores/as têm sido submetidos/as.

Uma outra professora fala sobre como estamos cada vez mais vinculados uns aos outros e ao mesmo tempo pouco sensíveis aos problemas dos outros: "Gostei muito da cena em que o robô cuida da senhora e de quando ela cuida dele! O que faz uma relação! Como estabelecemos vínculos até mesmo com máquinas. Como nossas relações são diferentes, dinâmicas, muda o tempo inteiro, por isso a vida é invenção".

\footnotetext{
${ }^{3}$ Coronavírus é uma família de vírus que causam infecções respiratórias, que provoca a doença chamada de coronavírus (COVID-19). O COVID 19, causou milhões de mortes no mundo, além de medos e necessidades de isolamento para evitar a proliferação do vírus.
} 


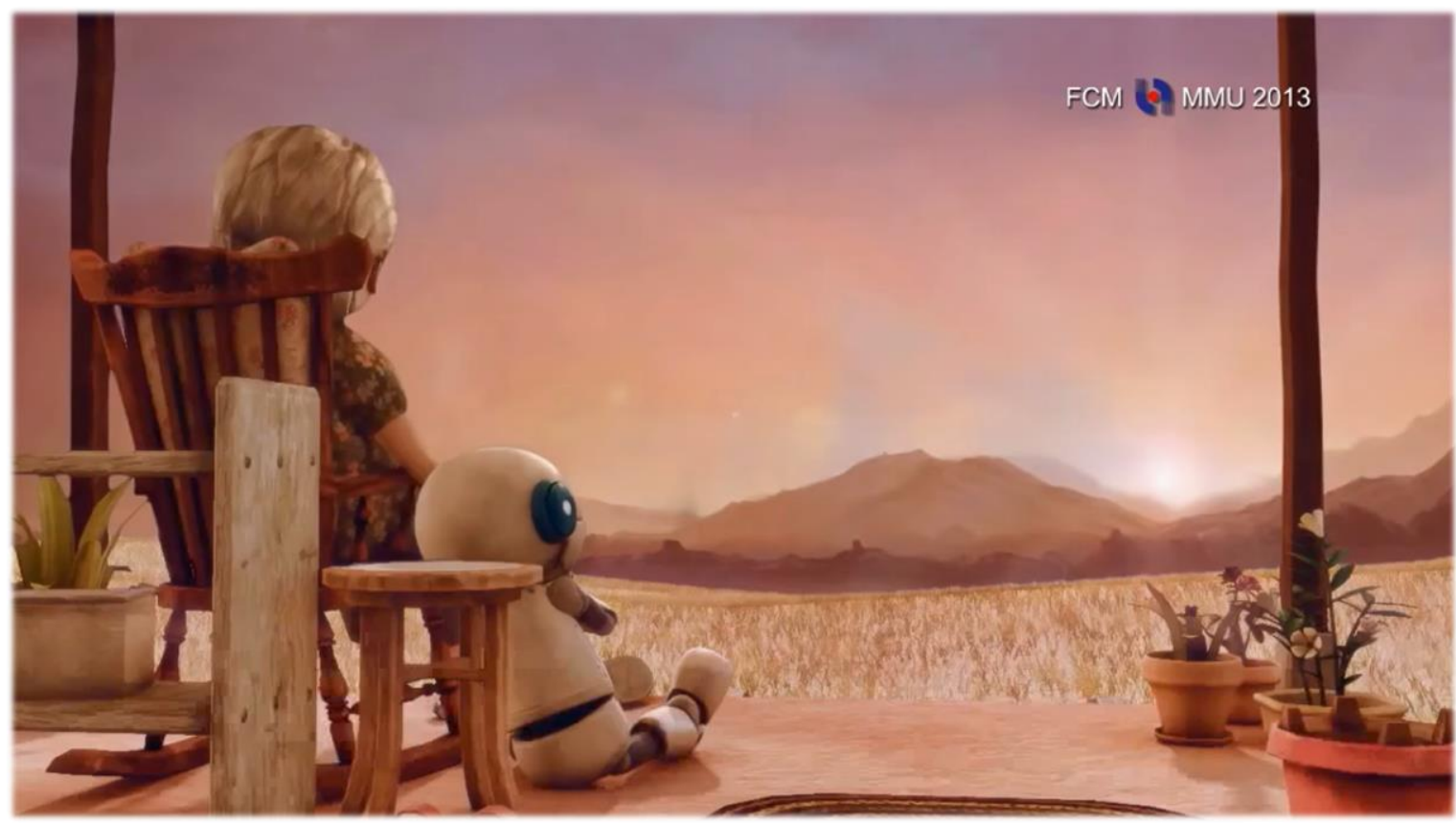

Imagem 2: Um cuidando do outro

Fonte: https://www.youtube.com/watch?time_continue=286\&v=O_yVo3YOfqQ\&feature=emb_logo

As narrativas ${ }^{4}$ dessas professoras possibilitaram a problematização das políticas de centralização e de padronização curricular, que tentam aprisionar e engessar os processos inventivos das escolas. A força das políticas de avaliação em larga escala, que atende, principalmente, aos grandes investidores de materiais didáticos, também, foi questionada. Mas, a força do intempestivo da amizade fez vazar a sensação de aprisionamento, trazendo fôlego para a luta cotidiana que fortalece a autonomia docente e o trabalho coletivo.

Uma professora diz:

A caixa que chegou de presente para a senhora idosa, me lembra o tanto de prescrições, livros didáticos e apostilas que são enviadas para as escolas, sem, ao menos, perguntar o que realmente as escolas estão precisando. Fiquei pensando com esse filme na coisificação do humano. O que fazemos quando somos colocados nesse lugar de coisa? Eu tenho uma criança que não quer entrar nas brincadeiras com os colegas, não interage, não se suja, recusa a participar das experiências. Aí fomos conversar com a família e perguntamos como ele era em casa. Eles disseram que era quieto também. Perguntamos se eles levavam a criança para passear, brincar. Eles perceberam que estavam interagindo pouco com o filho. Nós não temos todas as respostas, mas os caminhos vão aparecendo. Quando conversamos com os pais, com as colegas, a gente vai encontrando formas de ir resolvendo as questões cotidianas.

A nossa intenção, ao levar as imagens-cinema para esses encontros, era apostar que o signo artístico do cinema mobilizasse o pensamento das professoras. O nosso desejo era possibilitar um signo que forçasse as professoras a inventar novas ideias para as escolas e para

\footnotetext{
${ }^{4}$ As narrativas de professoras aparecerão entremeadas ao texto sem identificação de nomes, por entendermos que as imagens e as narrativas são agenciamentos coletivos de enunciação que nos fazem pensar e que potencializam as resistências coletivas e os processos de invenções curriculares.
} 
os currículos. Propiciar, portanto, a possibilidade de novos desejos coletivos por meio das composições. Nesse contexto, problematizamos: O que as imagens possibilitam pensar a respeito do trabalho docente? De que energia os nossos corpos necessitam para enfrentarmos os desafios cotidianos e driblarmos as tecnologias de governamento ${ }^{5}$ ?

As imagens da animação Changing Batteries como elemento disparador de redes de conversas, possibilitaram que as professoras verbalizassem sobre a complexidade do mundo e a importância da autonomia docente. Juntas perceberam quantas experiências são criadas todos os dias na escola, por meio dos encontros entre professoras e crianças, criticaram ainda, os currículos que se constituem para atender as demandas das datas comemorativas e, por fim, afirmaram que o que faz o corpo vibrar no cotidiano são as fabulações, as inventividades das crianças, a amizade e a artesania do trabalho docente.

Sobre isso uma professora disse:

Vi hoje na televisão uma reportagem de uma criança que alfabetizou o vendedor de picolé que trabalhava em frente a sua escola. Ele ficava há mais de 30 anos naquele mesmo lugar e somente essa menina se sensibilizou para ensiná-lo a ler. A emoção daquele senhor me afetou muito! Nesse mesmo jornal, apareceu uma mãe que perdeu a paciência com o filho e o abandonou no terminal. São nesses extremos que vivemos. A vida é muito complexa.

Uma outra professora entrou na conversação e disse:

É muito difícil, parece que vamos nos acostumando com essas coisas. Pensei na ideia dos robôs. Parece que estamos nos relacionando com robôs e como robôs, tamanha rigidez, tamanha dureza. O robô do filme parece mais humano que nós. Hoje eu estava conversando com um pai que pensou em tirar o filho da escola, devido ao processo de exclusão que a criança está vivendo nessa escola, pelo conjunto de pessoas que são insensiveis a experiências dessas crianças. Comenta-se sobre o filho do outro, mas não se deixa afetar pelo filho do outro. Estamos nos tornando cada vez mais individualistas, eu... eu... eu...

Assim, problematizamos a respeito dos afectos alegres, que acreditamos expandir a potência de ação coletiva, pedindo que verbalizassem sobre os encontros em que percebem que agem com mais autonomia, sobre os encontros que fazem o corpo vibrar. Dentre as diversas narrativas, uma professora destaca a força da amizade:

O que faz a gente acreditar na educação é escutar dos pais os efeitos do nosso trabalho diário. Quando vemos as produções das crianças. Outro dia, eu fiquei de longe, observando as crianças no parquinho. E vi um menino que há pouco tempo não saia de perto de mim. Ele começava a explorar mais a escola. Ele parecia acompanhar o movimento de um colega, onde um ia o outro seguia. Fiquei tão feliz de ver, como um amigo favorece o crescimento do outro.

Ao cartografar o que se passa entre os corpos, foi possível perceber que: as professoras desejam compor de forma mais coletiva, gostam de fabular com as crianças, mas que ainda se sentem pressionadas pela demanda de pais e dos dispositivos que chegam nas escolas para

\footnotetext{
${ }^{5}$ Entendemos tecnologias de governamento como as múltiplas formas e estratégias de se conduzir condutas, de si ou dos outros, de indivíduos ou populações.
} 
formatar as práticas educativas. Assim, apontam a necessidade de mais espaçostempos para trocar experiências, dividir as problematizações, ampliar os vínculos e as amizades.

Uma professora desabafa:

E essa história de livro didático na educação infantil? E tem gente que vem me dizer que isso é bom? Bom pra quê, bom pra quem? Gente, eu tenho horror a isso!!! Quem vai ter força pra barrar essa loucura? Temos que nos juntar aos movimentos, levar argumentos para discutir essa ideia lá na SEME.

Nos encontros de professoras com as imagens, presenciamos narrativas de indignações, tais como: "[...] é muito triste, quando trazemos uma questão para ser encaminhada e não temos escuta. Por exemplo, no início do movimento de greve dos professores, não tivemos apoio. Para negociar a reposição dos dias nos sábados foi tão difícil definir ações". Silêncios, narrativas de medos e tristezas, que se alternavam com os relatos de conquistas e de alegrias das conquistas e experimentações coletivas.

Nas redes de conversações, emergiam os agenciamentos coletivos de enunciação, isto é, as conexões, os fluxos de devires, os agenciamentos de desejos que contagiavam o coletivo a se renovar e se reinventar. No momento em que uma problematização era apresentada, surgiam relatos das diversas experimentações vivenciadas pelo coletivo, assim, a formação inventiva produzia resistências inventivas e novos movimentos curriculares.

Cada encontro apresentava uma peculiaridade, pois cada espaço, entendido aqui como lugar praticado (CERTEAU, 1994), se apresenta com a sua singularidade. O cotidiano escolar é campo micropolítico que consiste na criação de agenciamentos intensificadores dos processos de singularização, que produzem uma energia do desejo que movimenta indivíduos e grupos, possibilitando processos de desterritorialização, reterritorialização e criação. Nesse encontro com o filme Trocando as baterias, as professoras percebem o quanto precisam umas das outras, o quanto incomoda ver que as pessoas têm se tornado insensíveis aos problemas do outro e destacam a importância de expandir as redes de solidariedade nos cotidianos escolares.

Para Deleuze e Guattari (2012), não há território sem aberturas, linhas de fuga, vetores de saída. A desterritorialização ocorre por meio dos movimentos criados pelos agenciamentos na operalização das linhas de fuga e a reterritorialização se constitui como novos agenciamentos maquínicos de corpos e coletivos de enunciação. As imagens atuam como disparadoras de aberturas e linhas de fuga para novos processos de subjetivação. Vale ressaltar que, sempre que houver movimento de desterritorialização, haverá movimento de reterritorialização, ou seja, esses processos são indissociáveis.

Percebemos, portanto, que o encontro com as imagens do curta Trocando as baterias em redes de conversações a quebra dos clichês que carregam alguns regimes de "verdades" para a escola. A circularidade de novas problematizações, possibilitou pensar questões importantes para a constituição do comum e da coletividade, que se constitui e se enriquece na e com a experiência, desnaturalizando praticasdiscursivas por meio do encontro do pensamento com a diferença, que possibilita pensar outros possíveis para a educação.

Como afirmam Hardt e Negri (2016), entendemos comum à riqueza do mundo material, ar, água, os frutos da terra, a natureza, os conhecimentos, os códigos e toda a herança da humanidade a ser compartilhada. Para eles, “[...] uma democracia da multidão só é imaginável e possível porque todos compartilhamos do comum e dele participamos. As políticas neoliberais em todo o mundo têm buscado privatizar o comum, transformando os em produtos culturais. É necessário resistir as privatizações da informação e das ideias. A problematização apresentada

\footnotetext{
${ }^{6}$ Secretaria Municipal de Educação.
} 
pela professora de que estamos agindo com robôs e como robôs, possibilita pensarmos que processos de subjetivações têm se delineado nos espaços escolares. As professoras, por exemplo, ao questionarem a chegada dos livros didáticos na educação infantil, a reagirem às políticas de avaliação padronizada, a se recusarem parar as experiências com as crianças para cumprir as formalidades do Dia das mães, criam resistências e começam a entender a importância de se unirem em busca do bem comum.

Ao se recusarem agir como robôs e serem colocadas como robôs, se colocam em um movimento, denominado por Hardt e Negri (2016, p. 8) devir-príncipe, que quer dizer “"[...] o processo em que a multidão aprende a arte do autogoverno e inventa formas democráticas duradouras de organização". Assim as professoras expressam que desejam para a escola um corpo que pulsa e que vibra com as invencionices das crianças, um corpo autônomo, que se modifica, cotidianamente, por meio da força de seu coletivo.

Uma professora diz: "Eu fiquei menos impactada com a morte da velhinha do que quando o robô coloca a bateria e fica esperando o corpo voltar a vibrar. Acho que me impacta mais a morte em vida e, se não cuidarmos, é isso que produziremos com as nossas relações".

Ao perguntarmos sobre o que faz o corpo vibrar na escola e o que podemos fazer para expandir a força de ação coletiva, algumas professoras expressam suas percepções. Uma delas responde:

O que faz o coro vibrar são as relações. Vibramos com a alegria das crianças, com as atividades, com as brincadeiras, com tudo aquilo que acontece na escola, com as miudezas do cotidiano, [...] com o besouro que a criança encontra no parquinho e quer aprender as características daquele inseto. As conversas com os pais, mesmo na porta, mesmo correndo.

Uma outra complementa: "Precisamos acreditar no nosso trabalho, não deixar que a falta de sensibilidade tome conta, não deixar coisas chatas 'sugar' a nossa energia. A relação com as crianças é pura vibração. Deixar-nos contagiar com essa energia”.

O movimento criado com a pesquisa em espaços de formação de professoras, tendo as imagens cinema como disparadoras de processos de desterritorializações, reverberou em relações mais solidárias e acolhedoras, que criticam as atitudes individualistas e competitivas que atravessam o mundo e, consequentemente, as práticas docentes - fruto das políticas educacionais que premiam os professores que respondem melhor as formas de governamento e, que experimentam novas invenções curriculares. Gallo (2016, p. 42), pensa o cotidiano escolar como "[...] o entre-lugar da educação maior, aparelho de estado estratificante e segmentador e da educação menor, máquina de guerra nômade, alisadora de linhas de fuga". Do mesmo modo, acreditamos que as imagens cinematográficas com redes de conversações potencializam os cotidianos escolares liberando linhas de fuga para abertura de processos mais solidários na constituição de uma docência inventiva.

As lutas atuais não se dão em torno da natureza das instituições, mas da forma desejável de vida, como afirma Pelbart (2017). As insurreições emergem a partir de uma combinação de coragem, determinação, confiança em si, sentido estratégico e energia coletiva. Essa energia coletiva destacada por Pelbart, foi se constituindo nos encontros de formação cada vez que uma professora contava as suas experiências com as crianças, explicando como delineava as suas artes de fazer e de nutrir (SILVA, 2015). Uma energia que contagiava aquelas que ainda estavam com receios de se expressar, de contar as suas experiências curriculares. Uma energia que incitava a problematização de "supostas" verdades, que desestabilizava crenças, lançando aberturas nos corpos que foram produzidos para serem dóceis, mas que, no encontro com outros corpos, puderam se reinventar e se abrir para os movimentos inventivos curriculares. 
As imagens cinematográficas com redes de conversações, funcionaram nessa pesquisa como impulsionadoras de redes de amizade e de solidariedade, ampliando a potência de ação coletiva, mobilizadora da formação inventiva e das invenções curriculares. Assim como as moças-vagalumes, contadoras de histórias que faziam as crianças da vila sonharem, desejamos que as professoras possam renovar sempre os seus sonhos e os sonhos das crianças. Sonhos mobilizadores de dúvidas, de novas problematizações e com desejo de construir novas maneiras de ser e de estar no mundo

\section{Referências}

CARVALHO, J. M. Redes de conversações como um modo singular de realização da formação contínua de professores no cotidiano escolar. Revista de Ciências Humanas, v. 6, n. 2, p. 281293, jul./dez. 2006.

CARVALHO, J. M. O cotidiano escolar como comunidade de afetos. Petrópolis, RJ: DP et Alii; Brasília, DF: CNPq, 2009.

CARVALHO, J.; SILVA, S. K.; DELBONI, T. O currículo como corpos coletivos. Revista Currículo sem fronteiras, v. 18, n. 3, p. 801-818, set./dez. 2018.

CERTEAU, M. A invenção do cotidiano 1: artes de fazer. Petrópolis, RJ: Vozes, 1994.

DELEUZE. G. Conversações. São Paulo: Editora 34, 2010.

DELEUZE, G.; GUATTARI, F. Mil platôs: capitalismo e esquizofrenia, vol. 3. Rio de Janeiro: Editora 34, 2012.

GALLO, S. Em torno de uma educação menor: variáveis e variações. In: BRITO, M. R.; GALLO, S. (Org.) Filosofia da diferença e educação. São Paulo: Livraria da Física, 2016. p. 15-46.

HARDT, M.; NEGRI, A. Bem estar comum. Trad. Clóvis Marques. Rio de Janeiro: Record, 2016.

HATOUM, M. Um solitário à espreita: crônicas. São Paulo: Companhia das Letras, 2013.

KASTRUP, V. Conversando sobre políticas cognitivas e formação inventiva. In: DIAS, R. O. Formação inventiva de professores. Rio de Janeiro: Faperj, Lamparina, 2012.

PARAÍSO, M. A. O currículo entre formas e forças. Revista Educação, v. 38, n. 1, p. 49-58, jan.-abr. 2015.

PELBART, P. P. Aos nossos amigos. In: RAGO, M; GALLO, S. Michel Foucault e as insurreições: é inútil revoltar-se? São Paulo: CNPq, Capes, Fapesp, Intermeios, 2017.

ROLNIK S. Esferas da insurreição: notas para uma vida não cafetinada. São Paulo: Editora $\mathrm{N}-1,2018$.

SILVA, S. K. Cartografias das artes de fazer e de nutrir. Revista Instrumento: R. Est. Pesq. Educ., Juiz de Fora, v. 17, n. 1, p. 11-20, jan./jun. 2015. 
COMO IMAGENS CINEMATOGRÁFICAS COM REDES DE CONVERSAÇÕES PODEM MOVIMENTAR...

SPINOZA, B. Ética. Belo Horizonte: Autêntica, 2008. 